\title{
Los estudios sobre códices diplomáticos hispánicos. Confluencias historiográficas, metodológicas y sistémicas durante los ss. XVIII-XX
}

Alicia Sánchez Díez

Universidad Complutense de Madrid aliciasa@ucm.es

Fecha recepción 01.02.2017 / Fecha aceptación 06.03.2017

\section{Resumen}

Las dificultades metodológicas en los estudios sobre códices diplomáticos hispánicos, en su mayoría derivadas de la ausencia de grandes tratados sistémicos, comienzan levemente a solventarse, en estos últimos años, en buena parte debido al desarrollo de estudios comparativos avanzados y sistemas metodológicos multidisciplinares asistidos por herramientas tecnológicas, los cuales permiten diversificar los enfoques historiográficos tradicionales. A continuación se expone un análisis de las confluencias y divergencias, un examen de la evolución y mejoras en las metodologías aplicadas a los trabajos sobre este objeto de estudio a lo largo

\begin{abstract}
The methodological difficulties of research into Hispanic diplomatic codices, mostly arising from the lack of major systemic treatises, have begun to be resolved to a limited extent in recent years. This is largely due to advanced comparative studies and multidisciplinary methodological systems supported by technological tools, which both allow the diversification of traditional historiographic approaches. This paper sets out an analysis of the confluences and divergences, an examination of developments and improvements in the methodologies used to work on this subject of study over the last three centuries, showing
\end{abstract}


de los últimos tres siglos, demostrando su influencia y efecto, no siempre positivos, en las disertaciones actuales.

\section{Palabras clave}

Códices diplomáticos; cartularios; metodología; sistemática; cultura escrita; siglos XVIII, XIX Y XX. both the influence and effect, not always positive, in current dissertations.

\section{Key words}

Diplomatic codices; cartularies; methodology; systematic; science of writing and written objects; $18^{\text {th }}, 19^{\text {th }}$ and $20^{\text {th }}$ centuries. 


\section{Introducción}

Los actualmente denominados códices diplomáticos no han merecido siempre una especial atención por parte de los investigadores quienes quizá han dedicado mayores esfuerzos al estudio de documentos originales sueltos o unitarios, desde los ámbitos de la paleografía o la diplomática. Posiblemente, examinando estos objetos desde áreas codicológicas o filológicas hayan recibido mayor solicitud, considerando su valía textual u ornamental, en el caso de códices diplomáticos iluminados, pero no estudiando el manuscrito en todo su conjunto, como documento con materialidad propia, su estructura interna, la función intrínseca que presenta, su autoridad como fuente histórica, como tipo documental compuesto determinado y claramente diferenciado.

Se puede decir que, hasta el presente, los estudios relativos a estos manuscritos son prácticamente nulos. Si bien, contamos con numerosas ediciones de cartularios, becerros, tumbos, etc., en cuyos prólogos e introducciones se esbozan escuetas reseñas e informaciones generalistas, más a modo de preámbulo al objeto real de estudio que como investigación profunda sobre el tema. Se advierte además que dichas notas se repiten casi al pie de la letra, cual lugares comunes, a lo largo del tiempo, en los trabajos que se van presentando, sin apenas comprobar o profundizar sobre tales afirmaciones. Y, por supuesto, según se describa el enfoque bajo el cual el códice es examinado, así versará la anotación correspondiente. De esta manera, en un estudio relativo a la ornamentación de determinado cartulario, es posible encontrar alguna reseña que defina este tipo documental pero siempre encarada desde una óptica histórico-artística. $\mathrm{O}$ en el caso de un estudio filológico, la anotación o definición se verá influida por dicha orientación. Hecho, por otro lado, ciertamente lógico pero que ha venido constriñendo la dimensión general de estos documentos.

Hoy día, lentamente, las nuevas formas de acercamiento a este tipo documental van evolucionando. De aquellas antiguas notas, rudimentariamente definitorias, que hallamos en el Viage de Ambrosio de Morales, a saber, «... otro Libro que recopiló el mismo Pelagio, y es Historia de la Iglesia, y de la Ciudad de Oviedo, con poner en él todos los privilegios y bulas 
que los Sumos Pontífices otorgaron a la Iglesia y a la Ciudad. Con esto es verdaderamente Tumbo, que Tumbos llaman en Asturias, Galicia y Portugal, a sus libros semejantes, que en Castilla llamamos Becerros» ${ }^{1}$, a la moderna acepción normalizada de códice diplomático que ofrece la Comisión Internacional de Diplomática de la Unesco, «Colección de copias de sus propios documentos, establecida por una persona física o moral, que, en un volumen o más raramente en un rollo, transcribe o hace transcribir íntegramente, o en ocasiones en forma de extracto, los títulos relativos a sus bienes y a sus derechos y documentos que conciernen a su historia o a su administración, para asegurar su conservación y facilitar su consulta ${ }^{2}$, han pasado siglos, con sus cambios de paradigma, evolución y revolución en metodologías, enfoques, intereses, herramientas de trabajo, etc.

Así, el interés que los códices diplomáticos han suscitado entre los investigadores, a lo largo de la historia, ha dejado sus huellas en diversas manifestaciones que pueden ser consultadas en la actualidad y que van a permitir analizar los avances en las metodologías de trabajo y las epistemologías sistémicas, para esbozar un estudio de las confluencias y divergencias de las ópticas bajo las cuales los estudiosos de los últimos siglos se han acercado a estas fuentes.

Dicho estudio se expone en este artículo siguiendo un criterio evolutivo y cronológico, ciertamente descriptivo, como no podría ser de otra manera, concluyendo con una relación breve de consecuencias y resultados.

\section{Los inicios (siglos xVIII y xIx)}

En 1772, Campomanes escribía una extensa epístola a su erudito compañero, el benedictino José Ruete, sobre el escaso provecho de las anotaciones sueltas y los exiguos inventarios, con los que hasta el momento se contaba, de los «monumentos» (refiriéndose a documentos, diplomas y manuscritos), porque «solo conducen a algún objeto pasajero y, cuando se va a hacer uso de estas apuntaciones, se encuentran escasas o diminutas, sujetas a equivocación y de corto provecho» ${ }^{3}$.

Es, esta carta, un completo e interesante artículo en el que se expone la necesidad de instrucción de los monjes e investigadores dedicados a la diplomática en la correcta lectura e

1. A. Morales, Viage de Ambrosio de Morales por orden del Rey D. Phelipe II a los Reynos de León, y Galicia, y Principado de Asturias, Madrid, Guillermo Blázquez, 1985. Ed. facs. de la de Madrid por Antonio Marín, $1765,96$.

2. Commission Internationale de Diplomatique. Commission Internationale de Sigillographie, Diplomatica et sigillographica. Travaux preliminaires de la Commission Internationale de Diplomatique et de la Commission Internationale de Sigillographie pour une normalisation internationale des éditions de documents et un vocabulaire international de la diplomatique et de la sigillographie, Zaragoza, Institución "Fernando el Católico", 1984, 122. Misma definición en: Commission Internationale de Diplomatique, Vocabulaire Internationale de la Diplomatique, M. M. Cárcel, ed., Valencia, 1997, 35.

3. Epístola de Campomanes a José Ruete, sobre la colección de monumentos de antigüedades. Madrid, 16 de noviembre de 1772. En P. Rodríguez de Campomanes, Epistolario. Tomo I (1747-1777), Ed. de M. Avilés Fernández y J. Cejudo López, Madrid, 1983, 542. 
interpretación de los textos que manejan, la problemática en las copias galicanas, producida por sus abreviaturas y guarismos, las confusiones debidas a la ilegibilidad de los códices y documentos "consumidos por el tiempo», las dataciones, las confirmaciones y testigos, sobre la importancia de la correcta interpretación onomástica y la necesidad de contar con una biblioteca auxiliar para el uso de los investigadores. Pero, no se limita Campomanes a exponer el desconcierto reinante a la luz de sus propias exploraciones, sino que continúa analizando, con relativa profundidad, estos «monumentos» llegando a establecer incluso una clasificación, que explica y desarrolla, basada en los primeros descubrimientos del padre Ibarreta ${ }^{4}, \mathrm{y}$ entre los que se encuentran los códices diplomáticos. Es, en este momento, cuando se gesta en la Real Academia de la Historia, representado por dicho Ibarreta, un plan para el reconocimiento de archivos antiguos y la formación de lo que vino en denominarse una Diplomática Española, la cual incluiría la publicación de varios documentos, que, hasta el momento, no habían visto la luz pública.

A mediados del s. XIx José María de Eguren se refiere a estos códices con estas palabras: «Grande es la importancia, y en esta nación no conocida por cierto, de los tumbos o becerros y de los cartularios, libros que deben ser contados entre los manuscritos más interesantes de la Edad Media. Insertábanse en ellos los privilegios, donaciones y mercedes que se otorgaban a cada iglesia o monasterio, y toda clase de escrituras relativas a los mismos» ${ }^{5}$.

En su Memoria descriptiva, se encuentran numerosas noticias relativas al origen de los archivos eclesiásticos, la utilidad de los viajes para el enriquecimiento de los mismos y de las bibliotecas, la evolución de la escritura y la paleografía, así como de los tratados relativos a las mismas; estudia las ediciones facsímiles y las copias, ofreciendo noticias sobre centros custodios de valiosos manuscritos, sus fondos, las donaciones, etc. Advierte sobre la autenticidad y validez de copias y traslados, así como de trabajos historiográficos anteriores, como la Historia de Mariana de la cual apunta: «... debe ser leída con desconfianza» ${ }^{6}$. Acompaña sus afirmaciones con acertadas referencias al padre Flórez, padre Yepes, Ambrosio de Morales o al padre Luciano, así como con ejemplos de los tumbos de Sobrado, de Santiago, Poblet, Celanova,... ${ }^{7}$ El catálogo descriptivo que incluye, ordenado según tipologías documentales,

4. Domingo de Ibarreta (Pedroso, La Rioja, 1710 - Madrid, 1785). Benedictino abad de Silos y de San Martín de Madrid, erudito infatigable de la investigación paleográfica y más aún diplomática. Es considerada su gran obra su plan para la diplomática española de 1772; obra en 5 vols., al parecer no aceptada por su excesivo detalle.

5. J. M. Eguren, Memoria descriptiva de los códices notables conservados en los archivos eclesiásticos de España, Madrid, Rivadeneyra, 1859, 99.

6. Eguren, Memoria..., op. cit., viII.

7. Hoy día contamos con las ediciones de algunos de estos códices: P. Loscertales, Tumbos del Monasterio de Sobrado de los Monjes, Madrid, Dirección General del Patrimonio Artístico y Cultural, Archivo Histórico Nacional, 1976. A. Cabana, "O tombo da Catedral de Santiago: noticia do libro-rexistro medieval", en Homenaje a José García Oro, Santiago de Compostela, Universidad, 2002, 49-63. M. T. González, Tumbo $B$ de la Catedral de Santiago. Estudio y edición, Santiago de Compostela, Seminario de Estudios Galegos. Cabildo de la S.A.M.I. Catedral, 2004. M. Lucas, La documentación del Tumbo A de la Catedral de Santiago de Compostela. Estudio y edición, León, Centro de Estudios e Investigación "San Isidoro", 1997. J. M. 
aporta breves reseñas de numerosos códices custodiados en diversas sedes eclesiásticas españolas, dedicando un epígrafe exclusivo a los «Tumbos, becerros y cartularios» ${ }^{8}$.

Muy próxima en el tiempo, y continuando el estilo de análisis previo, es la publicación, en 1881, del historiador Foradada y Castán, en la Revista Contemporánea. Su Noticia de varios becerros y cartularios existentes en el Archivo Histórico Nacional ${ }^{9}$ lista o enumera, igualmente con sucintas noticias, códices de fueros, libros de óbito, cabreos, libros de profesiones, procesos, cronologías, becerros, tumbos, etc.

Tan solo cinco años después, a primeros de octubre de 1886, el profesor de la Escuela Superior de Diplomática, Vicente Vignau, recurre al gobierno solicitando la compra de ejemplares del primer tomo de una colección diplomática, que contiene, entre otros, el cartulario del monasterio de Eslonza y anuncia que, en un segundo tomo, se aportarán el glosario y los índices oportunos a dicha obra. Vignau, en su carta, deseaba saber cuánto tiempo debía aguardar para recibir apoyo oficial, pues era consciente de que del reconocimiento «público poco o nada pueden esperar las publicaciones de ese género». ${ }^{10}$

Este será un ejemplo de las penurias con las que un investigador decimonónico debía transigir al afrontar el estudio de semejantes documentos y resulta fiel reflejo de la situación de la investigación histórica y científica general del momento. Sin embargo, estas noticias ponen de manifiesto que, a pesar de ello, los cartularios seguían estudiándose.

La Real Academia de la Historia siempre apoyó y contribuyó a la edición de códices diplomáticos o trabajos relativos a ellos. Una muestra la encontramos en el cartulario de Santo Domingo de Silos, solicitado editar por el padre Fita Colomé con el aval de la Academia ${ }^{11}$. Su obra incluiría una historia del monasterio, el estudio del cartulario, un glosario e índices. Todo ello ilustrado con fotograbados. Estamos en el año 1891. El padre Fita ya había publicado con anterioridad otros estudios similares, como la carta o documento fechado en 1857 en el que, para ilustrar la historia del monasterio de Santa María de Piasca, describe brevemente el cartulario de Santo Toribio de Liébana ${ }^{12}$.

El Boletín de la Real Academia de la Historia sirve igualmente como trampolín a estudios más o menos desarrollados sobre determinados códices diplomáticos. En abril de 1898

Andrade, O tombo de Celanova: estudio introductorio e índices (ss. IX-XII), Santiago de Compostela, Consello da Cultura Galega, 1995.

8. Eguren, Memoria..., op. cit., 99.

9. J. Foradada, "Noticia de varios becerros y cartularios existentes en el Archivo Histórico Nacional, que pueden considerarse como principales monumentos de la historia y lingüística españolas", Revista contemporánea, 34/7, 1881.

10. Cf. V. La Fuente, "El Cartulario de Eslonza", Boletín de la Real Academia de la Historia, 9, 1886, 390392.

11. La carta de aval se encuentra publicada en: F. Fita Colomé [et al.], "Cartulario de Santo Domingo de Silos. Aval de la Academia”, Boletín de la Real Academia de la Historia, 19, 1891, 257-258.

12. Cf. E. Jusué, "El libro cartulario del Monasterio de Santo Toribio de Liébana", Boletín de la Real Academia de la Historia, 45, 1904, 409-421. 
se edita un estudio sobre los cartularios de Leire ${ }^{13}$. En octubre del mismo año, otro artículo versará sobre el cartulario de la Orden Templaria y Hospitalaria custodiado en el Archivo Histórico Nacional ${ }^{14}$.

Estos informes, y los que se encuentran con posterioridad, proporcionan estudios codicológicos primitivos, que difícilmente podrían parecerse a lo que hoy entendemos como tal y en los que se solía indicar brevemente: soporte escriptorio, número de páginas, lengua escrituraria y poco más. Se centran, fundamentalmente, en el contenido textual del documento, que enumeran pudiendo llegar a establecer criterios tipológicos de los documentos inclusos: privilegios reales, donaciones, concordias, etc. En algunos casos, el autor transcribirá el incipit de la obra y/o el explicit, si este es relevante.

Hasta el momento no se aprecia distinción real, por parte del investigador, entre un «cartulario», un «tumbo» o un «becerro»; más bien parece que cualquier manuscrito que incluya copias o regestos de documentos son tratados de igual manera y apodados «cartularios» $\mathrm{O}$ «códices» $\mathrm{O}$ «monumentos», englobando todos los conceptos en uno mismo.

Mientras tanto, y ya entrado el s. xx, el Boletín de la Real Academia de la Historia continúa publicando estudios similares a los anteriores: El tumbo de Valdeiglesias y su relación con Álvaro de Luna, en 1902 por Manuel de Foronda ${ }^{15}$; el libro cartulario del monasterio de Santo Toribio de Liébana, en 1904 por Eduardo Jusué ${ }^{16}$, en el que se reporta una descripción del monasterio, una breve historia y descripción del cartulario y la copia y análisis de cuatro cartas o diplomas inéditos de la sede lebaniega, entre otros.

Noticias y epístolas cursadas entre distintos ilustrados sobre algún cartulario en concreto o datos contenidos en los mismos también abundan en este siglo. La correspondencia erudita entre investigadores de esta época es fuente inagotable de información, en ocasiones inédita, que debiera ser siempre tenida en cuenta. Sirva de ejemplo esta, de Ramón Marcos y Sánchez al padre Fita, ofreciendo noticias sobre el becerro de Casasola ${ }^{17}$ :

13. M. Magallón, “Cartularios de Leire”, Boletín de la Real Academia de la Historia, 32, 1898, 257-261.

14. M. Magallón, "Templarios y Hospitalarios. Primer cartulario en el Archivo Histórico Nacional”, Boletín de la Real Academia de la Historia, 33, 1898, 258-266.

15. M. Foronda, "El Tumbo de Valdeiglesias y D. Álvaro de Luna", Boletín de la Real Academia de la Historia, 41, 1902, 174-181.

16. Jusué, "El libro cartulario... ", op. cit., 409-421.

17. CARTA de Ramón Marcos y Sánchez a F. Fita dándole noticias del Becerro de Casasola, los límites geográficos de esta dehesa; de la iglesia de Sta. Águeda y de los Baños de S. Miguel. Ciudad Rodrigo, 1913. Archivo Histórico de la Provincia de Castilla de la Compañía de Jesús, sin signatura. En este mismo archivo se custodia otra carta entre ambos de asunto similar. De nuevo, se debe señalar que ofrece referencias a datos que se incluyen en el becerro y que fueron solicitados por el padre Fita a Marcos en epístola anterior, pero no información sobre el becerro en sí. Imágenes de estos documentos se ofrecen en la Biblioteca Virtual Miguel de Cervantes, de la Fundación homónima, acompañando al registro catalogado bajo el título cit. supra: $<$ http://www.cervantesvirtual.com> [Fecha de consulta: 15 de enero de 2017]. 
[...] Pone a continuación lo que se dice de esa señora en el cap. 32 de la Historia de Ciudad Rodrigo 'María Adam, señora de Cerralvo: habiéndole muerto a su marido, se vistió de gerga y se ciñó con cinco vueltas de soga, y puso de no quitárselas hasta que fuese vengada la muerte de su marido don Sancho Pérez, y no teniendo', etc., etc. Si desea usted se la copie íntegra la relación de este episodio me lo dice y la remitiré. No lo hago ahora porque creo la tiene usted o está en el manuscrito de Cabañas, que cita; pues al decir el libro becerro que lo toma del capítulo 32 de la Historia de Ciudad Rodrigo, debe referirse a la de Cabañas. La losa sepulcral de esta señora se conserva cual la describe Cabañas [...] y sigue diciendo el becerro "No se dice aquí el año en que falleció esta María" [...]. Esto es lo que se encuentra acerca de doña María Adam en el becerro. También es curioso lo que refiere de la estancia de los franceses en tiempo de Napoleón [...].

\section{Los avances del siglo xx}

Sería posible llamar a la década de los años veinte el decenio de plata de las investigaciones «carturológicas», en cuanto al territorio peninsular se refiere.

En 1924 se publica, en Barcelona, el que se puede considerar primer manual sobre códices diplomáticos editado en España. Su autor, Francisco Nabot y Tomás, desde 1902 profesor en la Facultad de Filosofía y Letras de la Universidad de Barcelona de materias como Historia de la filosofía, Paleografía, Latín, Historia universal, y Numismática y Epigrafía, encargado también de la biblioteca de la facultad desde 1908, redacta este compendio, cuajado de noticias sobre multitud de códices diplomáticos, con una intencionalidad distinta: destacar la importancia de los mismos en la reconstrucción de la historia de España.

Nabot limita su estudio a los «códices diplomáticos». Es en este impreso donde, por vez primera, se encuentra tal denominación, a la que se refiere con los siguientes términos: «Limitamos nuestro estudio a los Códices diplomáticos, es decir, a aquellos que contienen documentos o índices y extractos de documentos de cualquier índole. No trataremos de todos los Códices diplomáticos, sino únicamente, de los llamados Cartularios, Becerros y Tumbos... ${ }^{18}$.

Esta delimitación asume la pertenencia de otros tipos de documentos en la categoría de códice diplomático, documentos que descarta del examen, según indica el mismo autor, por la abundancia de dichos materiales y por las dificultades de la investigación en archivos y bibliotecas. Estos a los que se refiere son: bularios pontificios, cartularios reales, de universidades, de órdenes militares, cabreos, necrológicos, obituarios, lumen domus, libros de renta, etc., que también definirá brevemente en el trabajo.

Por otro lado, la escueta definición de Nabot encierra en sí misma una primera clasificación de los códices según su contenido interno, a saber, aquellos que contienen las copias de los documentos originales íntegras, aquellos que únicamente cuentan con extractos o regestos de los mismos y, por último, los que solo los listan en una tabla o índice.

Como apunta en su definición, Nabot centra el estudio en los cartularios, becerros y tumbos; objetos que describirá o tratará de delimitar por oposición geográfica. Así, denomi-

18. F. Nabot, Los cartularios de las catedrales y monasterios de España en la Edad Media, Barcelona, $1924,7$. 
na «cartulario» al libro que contiene cartas y documentos limitando dicho término a España y países románicos. «Cartularis» o «cartorls» los llamarán en Cataluña. En Castilla y, debido a su encuadernación en piel de ternero, se llamarán «becerros» y en Galicia y Portugal «tumbos», describiendo la colocación de los mismos en las tablas de los armarios de los archivos y bibliotecas. Esta tipificación, prácticamente mantenida hasta nuestros días, es la primera en la que se intenta distinguir un tipo de códice de otro, atisbando ya la posibilidad de una diferenciación. Se recuerda que, hasta el momento, los historiadores y diplomatistas hablan de unos y otros términos como sinónimos, tan solo utilizando una denominación concreta al tratar un texto determinado y aun así, los errores que se venían cometiendo eran frecuentes.

Nabot expone la función que los códices diplomáticos tienen en su origen para con la institución (en su estudio, monasterios y catedrales) que los crea: «... facilitar la investigación documental y evitar, con el posible extravío o pérdida de los diplomas originales, la carencia de pruebas legales y autorizadas $»^{19}$. «... Para mejor asegurar la subsistencia de sus privilegios y derechos, tuvieron el buen cuidado, no solo de copiar las escrituras originales en sus cartularios, sino de sacar nuevas copias de estos, que por haberse perdido no pocos de los primitivos, les suplen y reemplazan actualmente» ${ }^{20}$.

En estos momentos se asegura la fidelidad de los documentos copiados en los cartularios y la «legalidad y validez de las copias cuyas formas primeras se perdieron $»^{21}$. Hoy día, se cuenta con estudios relativos a la tradición documental de estos objetos, en los que se discute el grado de veracidad o falsedad de los mismos. Lo que sí apunta Nabot, y parece admitido por la comunidad investigadora actual, es el hecho de que estos fueron reconocidos como verdaderos y válidos en pleitos, en los que la institución debía defender sus derechos y posesiones ante terceros.

Por otro lado, dedica unos párrafos al análisis de aquellos cartularios que ostentan disertaciones históricas, noticias biográficas, datos cronológicos, etc., a los que denomina «cartularios crónicas», otra nueva acuñación de un término que no se había planteado hasta el momento y que refleja otra de las funciones originarias de estos manuscritos, amén de la administrativo-jurídica anterior, y de una función de conservación y recuperación de los documentos originales deteriorados, expuesta en la cita anterior. Se refiere a una posible función memorística o histórica que será tratada ampliamente con posterioridad.

Quizá, la cuestión más controvertida del momento temporal en que Nabot realiza sus indagaciones versa sobre el origen de los cartularios. Aún los autores no se aventuran a una primera datación, tan solo aseguran, en el caso de Nabot, que «debió haberlos en los tiempos visigodos» $»^{22}$, no conservándose ningún cartulario anterior al s. $\mathrm{x}$.

Por último, y con solicitud manifiesta, Nabot ofrecerá novedosos apuntes relativos a su ejecución material, la disposición técnica de los cartularios, la impaginación, breves notas sobre la escritura, las abreviaturas, la calidad paleográfica y ornamental de los documentos,

19. Nabot, Los cartularios..., op. cit., 8.

20. Nabot, Los cartularios..., op. cit., 14.

21. Nabot, Los cartularios..., op. cit., 9.

22. Nabot, Los cartularios..., op. cit., 11. 
la iluminación de los títulos y letras capitales, las encuadernaciones y numerosos ejemplos ilustrando sus asertos.

Se admite asimismo la existencia de un orden interno del documento: geográfico, cronológico o variante, según la relevancia de los documentos originales que se copian de manera ordenada, ofreciendo prioridad a los privilegios pontificios y las bulas, a continuación los documentos reales y, por último, aquellos documentos de donaciones particulares.

Según Nabot, el análisis estilístico del texto permite deducir el dominio de la respectiva lengua documental del copista, para así vislumbrar focos de cultura y manifestaciones literarias en períodos de la alta Edad Media en que estas no eran las más frecuentes. La utilidad del cartulario para los estudios filológicos de la lengua es notoria. Igualmente, con el examen de las fórmulas o cláusulas documentales se vendría en conocimiento de una serie de detalles cancillerescos no percibidos hasta el momento. El valor de los cartularios desde el punto de vista bibliográfico se deja apreciar en la medida en que estos suministran datos referentes a libros y bibliotecas de los que no se tenía conocimiento alguno.

Cabe decir que estos análisis no se producen, como venía siendo costumbre, sobre un cartulario en concreto, sino que Nabot es capaz de generalizar sus conclusiones aportando un estudio complejo, fruto de una ardua tarea de síntesis y, por supuesto, reflejo del conocimiento acumulado durante años de estudio. El progreso que demuestra este trabajo sobre los anteriores es enorme.

Si se indicaba anteriormente que esta década de los años 20 fue prolija en publicaciones y estudios sobre los cartularios, no fue tan solo por los trabajos de Nabot y Tomás sino también gracias a las aportaciones de otro gran historiador del momento: Luciano Serrano y Pineda, O. S. B. (1879-1944), el que fuera nombrado abad de Silos en 1917, miembro de la Real Academia de la Historia los últimos cuatro años de su vida, la que dedicó plenamente al estudio y edición de fuentes medievales para la historia.

La mayoría de sus publicaciones se encuentran auspiciadas y editadas por el Centro de Estudios Históricos. En ellas se hallan estudios formales de tales códices y documentos, así como curiosas noticias relativas a su devenir histórico. Tan solo una cuestión deberán tener en cuenta los nuevos investigadores que se enfrenten a su obra, y es el hecho de que el padre Luciano entiende y titula «cartulario» a su obra, a su propia investigación, cuando puede que su estudio no incluya exactamente el cartulario que intitula su trabajo. Verbigracia, en el caso de la publicación bajo el título de El Cartulario de San Pedro de Arlanza ${ }^{23}$, el padre Serrano comenta, transcribe y estudia el becerro de Arlanza a través de diversas noticias, pero también de numerosos documentos, dispersos en diferentes sedes custodias, relativos al monasterio. A todo su estudio y recopilación de fuentes lo denomina "cartulario de Arlanza». De igual manera, en su obra: El Cartulario del Monasterio de Vega ${ }^{24}$, incluye escrituras anteriores al s. XII, conservadas en el monasterio y en el Archivo Histórico Nacional, pero también de la Colección Sobreira, que se custodiaba en la Real Academia de la Historia y del «libro de los

23. L. Serrano, Cartulario de San Pedro de Arlanza, Madrid, 1925.

24. L. Serrano, Cartulario del Monasterio de Vega, con documentos de San Pelayo y Vega de Oviedo, Madrid, 1927. 
vicarios» (becerro posterior, datado en el s. XVII). No menciona ningún cartulario ni becerro de la época, sino que con toda la documentación recopilada, las transcripciones y las noticias, forma lo que él mismo denomina «cartulario de Vega».

Esta manera de entender el concepto de "cartulario», como conjunto de documentos de una institución, elenco de fuentes primigenias de la misma, colección diplomática, y no como el objeto o documento con materialidad propia que entendemos hoy, nos acerca a la manera de pensar y afrontar, de los historiadores de la época, esas fuentes, su percepción de las mismas, entendiendo como "cartulario» la colección formada por los documentos incluidos en el cartulario propiamente dicho, más aquellos otros conservados aparte, siempre que correspondan a la misma entidad o institución y a la misma edad histórica, con fines de publicación conjunta ${ }^{25}$. Aun así, los datos ofrecidos en las investigaciones del padre Luciano y la calidad de sus trabajos son incuestionables.

Este análisis continuado de las metodologías de estudio aplicadas a los códices diplomáticos a lo largo de los últimos tres siglos, se debe detener en la mitad de este s. xx en un documento que, quizá por la óptica desde la cual se afronta, pueda llamar la atención, pero que, debido a su calidad y al contenido del estudio, apunta el avance que venía consiguiéndose en cuanto a la conceptualización y sistematización de los términos se refiere. Se trata del artículo de Font Rius, en la Nueva Enciclopedia Jurídica ${ }^{26}$, bajo el vocablo Cartularios. Cuatro hojas a dos columnas, en las que analiza el concepto y clases de cartularios, la razón de ser de los mismos, su antigüedad, el valor jurídico y su utilidad e interés. Rius mantiene el concepto y clasificación aportados por Nabot. De las funciones, que deduce de los mismos, destaca el autor el valor jurídico, no obstante, aun aceptando las tesis de Nabot, cita el parecer de Mosén José Rius, el cual discrepa de la siguiente manera: «... la necesidad de poseer copia de los títulos o privilegios para poder presentar los originales en juicio, ya que es indudable que serían estos los dotados de autenticidad jurídica y, por tanto, con valor probatorio, aparte de que resultará más cómodo aportar en juicio los originales que no los pesados volúmenes de los Cartularios» ${ }^{27}$.

El autor apoya su tesis, alegando la falta de originales por este motivo; los continuos viajes de los documentos a las chancillerías.

Sean unos u otros los que van a la magistratura, es este trabajo uno de los primeros en donde se pone en tela de juicio la veracidad de las copias de los códices diplomáticos, sin menoscabo de las opiniones vertidas por Floriano Cumbreño en su Curso general de paleografía, en el que ya tachaba a la mayoría de los cartularios, especialmente a los monásticos,

25. En líneas anteriores se apuntaba una noticia sobre la publicación, en 1885, de lo que el propio autor titula: Cartulario del Monasterio de Eslonza, por Vicente Vignau y que, como explica Vicente de La Fuente en su informe a la Real Academia de la Historia en 1886, está compuesto, en realidad, por «una colección diplomática, que contiene el Cartulario del monasterio de Eslonza». Cf. La Fuente, "El Cartulario... ”, op. cit., 390 y V. Vignau y Ballester, Cartulario del Monasterio de Eslonza. Primera parte, Madrid, 1885.

26. C. E. Mascareñas, Nueva Enciclopedia Jurídica, Barcelona, 1951, t. 3, 745-748.

27. Mascareñas, Nueva Enciclopedia..., op. cit., t. 3, 746.

Revista de historiografía 27, 2017, pp. 239-263 
como «inverecunda obra de monjes falsificadores» ${ }^{28}$. La problemática relativa a la tradición documental y el valor jurídico de los códices diplomáticos se arrastra hasta nuestros días ${ }^{29}$.

Se mencionará con posterioridad, sin embargo no es posible considerar completo este capítulo y siglo xx sin sacar a colación el artículo Cartularios incluido en el Diccionario de Historia Eclesiástica ${ }^{30}$ del profesor José Manuel Ruiz Asencio, el cual, al hilo del apunte anterior, subraya la necesidad de cotejar los documentos copiados en los códices con los originales, la crítica diplomática y la profundización en las lecturas que de ellos se realiza, para la obtención de resultados rigurosos.

Abarca, Ruiz Asencio, desde entonces y hasta nuestros días, todos los ámbitos y aspectos que estos manuscritos pueden ofrecer en sus numerosos estudios, no solo de códices diplomáticos, sino relativos a documentos de diferente índole, becerros de Valpuesta, documentos y códices de San Román de Entrepeñas, manuscritos de la catedral de Palencia, actas de las Juntas de Álava, documentación visigoda y bajo medieval, documentación de índole jurídica, administrativa o literaria, etc., legando a los historiadores venideros ediciones y estudios dotados de alta calidad y contenido científico de fuentes para el estudio del medievo ${ }^{31}$.

Se finaliza este epígrafe apuntando la colosal labor de edición de fuentes que, durante todo el s. Xx, desarrolló la Escuela de Estudios Medievales del Instituto de Historia «Jerónimo Zurita», dependiente del Consejo Superior de Investigaciones Científicas (CSIC).

La edición de fuentes y la publicación de documentación medieval en Europa se magnifican en este periodo en Alemania e Italia, pero especialmente en Francia. Se trata del siglo del aperturismo, en materia de archivos, a la investigación. El nacimiento del École Nationale des Chartes y «la publicación de la colección Documents inedits relatifs à l' histoire de France, y Alemania, con la Monumenta Germaniae Historica, llegando a ser en ambas una auténtica

28. A. Floriano, Curso general de paleografía y paleografía y diplomática española, Oviedo, 1946, 244.

29. Cf. M. J. Sanz, "Cartularios: historia y falsificación histórica”, en La memoria histórica de Cantabria, Edición a cargo de J. A. García de Cortázar, Santander, 1996, 147-153.

30. J. M. Ruiz, “Cartularios”, en Q. Aldea Vaquero [et al.], Diccionario de Historia Eclesiástica de España, Madrid, 1972, vol. 1, 368-370.

31. J. M. Ruiz, “Los cartularios de Valpuesta”, Estudios Mirandenses: Anuario de la Fundación Cultural "Profesor Cantera Burgos", 24, 2004, 354-381. J. M. Ruiz, I. Ruiz y M. Herrero, Los becerros gótico y galicano de Valpuesta. Volumen I. Estudio, edición e índices. Volumen II. Reproducción fotográfica del Becerro Gótico de Valpuesta (AHN, Códices, 1166), Burgos, Instituto Castellano y Leonés de la Lengua, 2010. J. M. Ruiz, "Documentos y códices altomedievales de San Román de Entrepeñas”, en Actas del I Congreso de Historia de Palencia: Castillo de Monzón de Campos, 3-5 Diciembre 1985, Palencia, 1987, vol. 2, 9-50. "Documentos sobre los manuscritos medievales de la Catedral de Palencia”, en Actas del II Congreso de Historia de Palencia, 27, 28 y 29 de abril de 1989, Palencia, 1990, vol. 2, 11-52. "Las Actas de las Juntas Generales de Álava como fuente para la historia de Álava”, en Ponencias y mesas redondas: Congreso Internacional sobre Sistemas de Información Histórica, 6, 7 y 8 de noviembre de 1997, Vitoria-Gasteiz, 1998, 197-206. J. M. Fernández y J. M. Ruiz, Colección documental del archivo de la Catedral de León (775-1230). Vol. 7, León, 2002, entre otros. 
empresa nacional. Su importancia es aún mayor si tenemos en cuenta que influyeron en gran medida en España» ${ }^{32}$.

En la España de comienzos de siglo, la Escuela Superior de Diplomática es absorbida por la Facultad de Filosofía y Letras de la Universidad Central, la Colección de documentos inéditos para la historia de España, que venía editando la Real Academia de la Historia desde 1842 ha dejado de publicarse y son la Junta para la Ampliación de Estudios e Investigaciones Científicas, el Centro de Estudios Históricos y el Instituto de Estudios Medievales (fundado con posterioridad a instancias del prof. Sánchez Albornoz), los que recogen el testigo. Este último será, precisamente, el encargado de la edición de los Monumenta Hispaniae Historica, a semejanza de los Monumenta alemanes y franceses ${ }^{33}$. En 1939 nacen, en el marco de creación del CSIC, el Instituto de Historia «Jerónimo Zurita» y la Escuela de Estudios Medievales. Esta última será la facultada para continuar la publicación de los Monumenta, labor que nunca se llevará a cabo pues, como indica la prof. Mendo,

la edición de documentos por su otorgante y ordenados cronológicamente, según los criterios de Böhmer, exigía dedicar mucho tiempo a la fase previa de recogida de material. Por otro lado, cierto número de los documentos altomedievales conservados presentan graves problemas de datación, amén de los consabidos lexicográficos. La conjunción de estos factores llevó a los miembros de la Escuela a juzgar más oportuna la publicación exhaustiva de algunos fondos documentales y textos de especial importancia ${ }^{34}$.

En el año 1942, el Consejo Superior de Investigaciones Científicas aprobaría la creación de secciones departamentales de la Escuela en Valencia, Pamplona y Barcelona dotadas de autonomías propias y capaces de coordinar trabajos de edición a escala supranacional. Fueron muy numerosos los fondos, documentos, libros, colecciones documentales, ... estudiados y editados gracias a estos institutos, no obstante y lamentablemente, con relación a la edición de grandes catálogos o índices, «estos primeros proyectos de gran envergadura, quizá por esto mismo, se perdieron $»^{35}$.

Paralelamente y por lo que se refiere al ámbito bibliográfico y al estudio y catalogación de la producción libraria nacional, esta insuficiencia resultaría igualmente notoria. Se carece actualmente de repertorios, inventarios o catálogos, que permitan conocer el alcance del patrimonio gráfico conservado. La elaboración de tales instrumentos, en boca de la profesora Elisa Ruiz y con palabras que podrían ser trasladadas al entorno documental,

Es un objetivo prioritario que no necesita ninguna justificación. Mientras no dispongamos de tales medios, estaremos incapacitados para reconstruir la trayectoria del libro manuscrito

32. C. Mendo, "La Escuela de Estudios Medievales: su labor de edición de fuentes”, Hispania. Revista española de historia, 175, 1990, 600.

33. Mendo, "La Escuela... ", op. cit., 602.

34. Mendo, "La Escuela... ”, op. cit., 603-604.

35. Mendo, "La Escuela... ”, op. cit., 606. 
hispánico en todos los órdenes. Por el momento, tenemos que limitarnos a abordar aspectos parciales pues, en efecto, los resultados obtenidos en nuestras investigaciones siempre serán provisionales y de valor relativo hasta que conozcamos en su conjunto la entidad y naturaleza de nuestro patrimonio ${ }^{36}$.

Al hilo, la colección Fuentes y estudios de historia leonesa, que inicia sus publicaciones en 1969, declarará como intenciones la recopilación de trabajos de «seria» investigación histórica sobre temas leoneses y «la publicación, por un lado, de 'fuentes', como colecciones documentales, catálogos, inventarios, etc., que puedan ser utilizados por los investigadores, $y$, por otro lado, a 'estudios' que nos ofrezcan el fruto de una investigación histórica» ${ }^{37}$.

Fernández Catón dirige esta monumental obra con Ruiz Asencio, Sánchez Albornoz, Prieto Prieto y Sáez Sánchez, entre otros grandes notables, a su lado. La participación de Emilio Sáez sería fructífera pero breve en esta empresa como se verá a continuación.

En los años cuarenta el prof. Sáez emprendería la tarea de transcribir y estudiar la documentación altomedieval de la catedral de León junto a Justo Pérez de Urbel, Sánchez Belda, Vázquez de Parga y Sánchez Candeira, bajo el auspicio del CSIC y del Centro de Estudios e Investigación «San Isidoro» de León. Su marcha a Barcelona en el año 58 deja en suspenso este propósito hasta que, en 1983, Fernández Catón le propone retomar e incorporar el trabajo realizado hasta la fecha al nuevo proyecto y colección leonina (mencionado en el párrafo anterior). En estos momentos los profs. Ruiz Asencio y Prieto Prieto se encontraban ya inmersos en el estudio del tumbo de León, Catón en el catálogo del Archivo Histórico Diocesano, Concepción Casado en la colección diplomática de Carrizo y Marta Herrero y Fernández Flórez en la voluminosa y compleja colección diplomática de Sahagún. Una empresa que sin duda recoge el «espíritu monumenta» citado con anterioridad y del que el propio prof. Fernández Catón, en la presentación al primer volumen dedicado a la documentación catedralicia, dice (al comentar la España Sagrada de Flórez y Risco): «aquella empresa de estos dos agustinos del siglo xviII pudiera haber sintonizado con el movimiento europeo surgido para la publicación de las fuentes del pasado histórico, como se hiciera en los Monumenta Germaniae Historica, ¡lástima que no fuera así!» ${ }^{38}$.

36. E. Ruiz, Introducción a la codicología, Madrid, 2002, 27.

37. E. Sáez, Colección documental del archivo de la catedral de León (775-1230). I (775-952), León, 1987, pp. finales del vol. dedicadas a publicitar la colección y los números ya editados.

38. Sáez, Colección documental..., op. cit., x. 


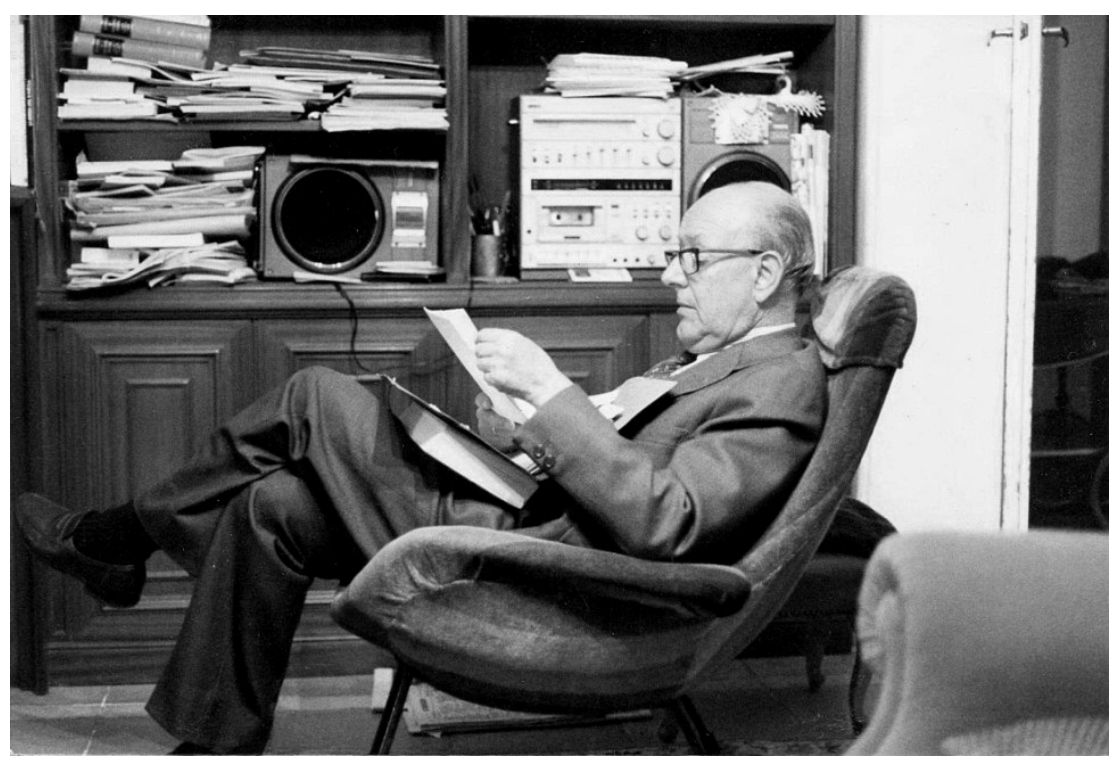

Imagen 1. Emilio Sáez (1917 - 1988). ${ }^{39}$

En 1987 sale de la imprenta el primer volumen de los dos que contendrán la fracción de documentación de la catedral de León asignada a Emilio Sáez ${ }^{40}$, la que comprende los años 775-985, puesto que los profs. Riesco y Catón se encargarían de la documentación bajomedieval ${ }^{41}$. Para este primer volumen contaría con la inestimable asistencia de su mujer, Amelia Sánchez López, en las tareas de transcripción; Margarita Cantera Montenegro, en la preparación y revisión de materiales y corrección de pruebas; y de una joven coadjutora Concepción Mendo Carmona, a la sazón estudiante de tercero de carrera cuando inició su colaboración en transcripciones, revisiones, búsqueda de libros, preparación de índices, etc. Es de especial valoración el completo estudio de la tipología diplomática, cronología, procedencia y tradición de la documentación presente en la colección documental, amén de los valiosos 11 apéndices y 2 índices que contiene.

Un año más tarde y a punto de ver la luz el segundo volumen, Sáez fallece en un inesperado accidente automovilístico. Será su hijo Carlos quien, favorecido por el mismo vigor científico de su padre, consiga finalmente sacar a luz dicho volumen en $1990^{42}$ y hacerse cargo de los numerosos proyectos iniciados por aquel.

39. Imagen cedida por C. Mendo, de su archivo privado.

40. Sáez, Colección documental..., op. cit.

41. Fernández y Ruiz, Colección documental..., op. cit.

42. E. Sáez y C. Sáez, Colección documental del archivo de la Catedral de León (775-1230). II (953-985), León, 1990. 
Si bien Emilio Sáez no centraría su interés en un códice diplomático concreto, sí que podemos considerarle uno de los grandes investigadores en fuentes documentales medievales de su tiempo. Como veremos a continuación será su hijo, el profesor Carlos Sáez, quien dedicará todo el conocimiento adquirido tras una vida de estudio de numerosísimos códices, a la conceptualización generalista de los mismos.

Finalmente, la magna colección leonina referida seguiría publicándose hasta día de hoy. Con más de 100 volúmenes, es considerada uno de los repertorios especializados más notables por la calidad científica tanto de sus textos como de los autores que los firman.

\section{Los estudios, metodologías y conceptualizaciones actuales}

Las ediciones de códices diplomáticos se suceden en el tiempo. Numerosos autores, en las introducciones a dichas publicaciones, verterán su opinión sobre estos documentos, definirán sus cartularios y tumbos utilizando, en su mayoría, los asertos expuestos hasta el momento. Las observaciones sobre los casos peninsulares más importantes adquieren una profundidad hasta el momento no alcanzada por especialistas anteriores, las formas de acercamiento a estos manuscritos han evolucionado y las nuevas metodologías paleográficas y diplomáticas dan sus frutos en las investigaciones que se presentan. Los cartularios de Valpuesta, los becerros de Sahagún, los tumbos de Santiago o León, el liber feudorum, etc., se encuentran en el punto de mira no solo de diplomatistas, sino también de historiadores del arte, filólogos e historiadores en general, que encuentran en ellos objeto de estudio y fuente de inspiración para investigaciones paralelas.

En la década de los cincuenta nace Carlos Sáez Sánchez. Profesor de Paleografía y Diplomática en la Universidad de Alcalá de Henares, desde su creación en 1978, logra consolidar el área de Ciencias y Técnicas Historiográficas en la misma, formando a sucesivas promociones de estudiantes en materias como la Paleografía, Diplomática y Archivística. Con él, heredero de la misma inquietud por las fuentes medievales que su padre, el citado historiador medievalista Emilio Sáez Sánchez, se alcanza la edad de oro de los estudios en esta materia.

Son profusos los artículos publicados por Carlos Sáez que se pueden encontrar en revistas, anuarios y manuales, nacionales y extranjeros; todos ellos reflejando unas mismas ideas que se tratará de resumir a continuación y que constituyen una de las más actualizadas visiones, y revisiones, de los códices diplomáticos con la que se cuenta a día de hoy.

En primer lugar, asienta la denominación «códice diplomático», que venía utilizándose tímidamente desde el siglo anterior, para nombrar a cualquier manuscrito de esta índole. Establece una distinción tajante entre «registro» y «cartulario», siendo este primero el que copia, de manera íntegra o abreviada, los documentos que ha expedido una institución y, el segundo, el que contiene aquellos recibidos por la institución.

La voz «cartulario», derivada de carta o cartula, equivale pues a colección de documentos y, quizá también en su momento de creación, a archivo: «La mención más antigua que conocemos habla de cartarios, o lugar donde se guardaban las cartas, y aparece en el siglo $\mathrm{x}$. Se trata de un documento portugués que dice: 'nostras cartas que in ipso nostro Kartario 
resonat' (...) es cierto que hoy aún el idioma portugués conserva el significado de archivo para la palabra cartorio» ${ }^{43}$.

Al hilo de esta cita es necesario indicar que aquí, en la península, existen del mismo modo referencias, datadas en el mismo s. $\mathrm{x}$, en las que la denominación «cartorio» se aplica al archivo custodio de la documentación. ${ }^{44}$

Sáez considera el término «tumbo», en especial utilizado en Galicia y Portugal, relacionándolo con el hecho de guardar dichos códices en un pequeño arcón de madera, semejante a un sepulcro, de donde derivaría el sintagma: «libro de tumbo». El término «becerro», una vez más, procederá del material y tipo de encuadernación utilizada, piel de origen bovino u ovino. Igualmente nominativos como «libro verde», «libro de la regla colorada», «tumbo negro» de Astorga, derivan de dicha encuadernación. Cuando el contenido del cartario se presenta ordenado de manera alfabética podría recibir el apelativo de «abecero»y, si está compuesto por noticias abreviadas de los documentos, en la corona de Aragón, se les viene llamando «cabreos» 0 «capbreus».

Sáez establece una tipología basada en el contenido material del códice, sin menoscabo de la tradicional jerarquización que los venía distribuyendo en: eclesiásticos, civiles y privados. La nueva organización distingue tres tipos:

El primero, y más primitivo, será aquel que cuenta con originales cosidos entre sí formando un volumen, un «mazo» de pergamino con dos tapas, a modo de carpeta, en donde a las piezas mayores se les realizaba un orificio para la sujeción con anillas. En el segundo tipo se encuadran los códices que contienen las copias íntegras de los documentos originales de la institución productora. Según el autor, esta disposición procedería de Alemania, donde ya se cuentan desde el s. Ix. En la península no encontramos ejemplos de este tipo hasta finales de XI, sin embargo, en él se incluyen los cartularios más estudiados y apreciados de nuestros archivos (León, Sobrado, Celanova o Sahagún). El tercer y último arquetipo sería el compuesto por los códices que únicamente contienen noticias, resúmenes, regestos o extractos de los originales, pero no el texto al completo. Este modelo predominará en épocas modernas, aunque contamos con ejemplos de gran interés, como el famoso registro de Corias ${ }^{45}$, del s. XIII.

Por otra parte, los cartularios hispanos separan documentos reales, pontificios, episcopales y particulares, que a su vez pueden dividirse por dominios señoriales. Según Sáez, esta norma «es paralela a otra, que organiza los códices diplomáticos por zonas geográficas» ${ }^{46}$, como sucede en los tumbos de Celanova y Sobrado.

43. C. Sáez, "Origen y función de los cartularios hispanos", Anuario del Centro de Estudios Históricos "Prof. Carlos S. A. Segreti”, 5, 2005, 38.

44. Cf. C. Mendo, "El pensamiento archivístico medieval. Una página de la historia de la cultura a través del fondo documental de la Catedral de León", en Pensamiento medieval hispano. Homenaje a Horacio Santiago-Otero, J. Soto Rábanos coordinador, Madrid, 1998, vol. 1, 613, nota 85.

45. Cf. A. García, El Registro de Corias: estudio y edición, Oviedo, 2000.

46. C. Sáez, "Ordenar y conservar en la catedral de Sigüenza (ss. XII-XIII)", en Anexos de Signo. Paisajes de cultura escrita, Carlos Sáez (editor), Alcalá de Henares, 2001, 83. 
Similar clasificación a la aportada por Sáez la encontramos en la obra del portugués Vitervo, la cual, si bien adolece de una definición de «cartario» extremadamente sucinta, sí aporta una sistematización acertada y unas observaciones acerca del valor jurídico y grado de falsedad de los mismos destacables:

Tres especies havia de Cartarios: a primeira constava dos proprios originaes encadernados, e compostos em fórma de livro: a segunda continha as copias authenticas, e collacionadas com os mesmos originaes, que por serem escriptos á pressa, e por notarios pouco habeis, poderiam com o tempo vir a ser pouco intelligiveis: a terceira finalmente so nos offerece a summa, e compendio dos originaes; omittindo-se muitas circumstancias, usando os compiladores dos seus termos, e frases, e tal vez inferindo relaçôes arbitrarias, segundo os seus interesses, e paixôes ${ }^{47}$.

Una pregunta que aún continúa formulándose entre los círculos y sociedades de ciencias historiográficas viene siendo la razón por la cual no todos los documentos de un archivo, un monasterio o una institución, son copiados en un cartulario. El estudio del origen de los códices diplomáticos y su función primigenia sigue abierto.

Fernández Catón ${ }^{48}$ halla un primer fundamento en la ilegibilidad de la escritura visigótica por parte de los clérigos, al ser esta, poco a poco, sustituida por la gótica. En algunos incipit se recoge esta causa como motivo de su producción. José Manuel Ruiz Asencio, en su artículo sobre los cartularios de Valpuesta y en sintonía con el traslado del becerro gótico valpostano al nuevo o galicano, expone que se pretende: «poner a disposición de la institución los documentos principales del Becerro Gótico, obviando el mal estado de conservación de la escritura que presentaban muchos de los viejos folios y, sobre todo, la dificultad de lectura que ya sin duda ofrecía a los hombres del siglo XIII la escritura visigótica documental» ${ }^{49}$.

Una segunda motivación estaría relacionada con la inestabilidad política de los reinos castellano y leonés. Esta idea es ampliamente desarrollada por la profesora Mendo Carmona en sus aportaciones infra cit. Lo que sí parece cierto, también en estos momentos, es que la defensa de los derechos y propiedades de las instituciones es la que realmente lleva a la copia de documentos: «El prólogo del Libro Tumbo de pergamino del monasterio gallego de Oseira, confeccionado en 1473, enumera asimismo las guerras, los pleitos y la dejadez de la justicia real, que habían producido no pocas pérdidas de bienes al monasterio, pero sobre todo los repetidos asaltos del archivo por parte de señores temporales, que causaron la desaparición de muchos documentos» ${ }^{50}$.

47. J. Santa Rosa, Elucidário das palavras, termos e frases que em Portugal antigamente se usaram e que hoje regularmente se ignoram. Obra indispensável para entender sem erro os documentos mais raros e preciosos que entre nós se conservam, Lisboa, A. J. Fernandes Lopes, 1865, 169.

48. J. M. Fernández, El llamado Tumbo Colorado y otros códices de la Iglesia Compostelana. Ensayo de reconstrucción, León, 1990.

49. Ruiz, "Los cartularios de... ”, op. cit., 364.

50. C. Sáez, "Origen y función de los cartularios: el ejemplo de España”, Gazette du livre medieval, 46, $2005,17$. 
La conservación de la documentación, se atisba como la causa fundamental de su producción.

Hasta el momento, las funciones principales de un cartulario, estudiadas por Sáez, vienen siendo las tradicionalmente aceptadas. No obstante, este estudioso vislumbra otras, a las que ciertos códices diplomáticos apelan.

El deseo de ostentación de algunos comitentes, como podrían ser aquellos de las sedes compostelanas, ovetenses o leonesas, en sus libros de gran lujo (libro de las estampas, liber testamentorum y tumbo A), pretenden, con sus orlas y miniaturas, demostrar la grandeza y riqueza de sus sedes y prelados.

El trabajo de Galván Freile sobre el libro de las estampas de la catedral de León ${ }^{51}$, apoya, bajo una óptica principalmente histórico-artística, dicho juicio. Contribuye este autor con una breve introducción al códice diplomático, su definición, ordenación interna y finalidad del mismo. Al respecto, indica que, si bien la principal función de estas obras es la de reunir la documentación más relevante para asegurar su conservación y facilitar su consulta, «otro aspecto importante, relacionado con la finalidad de algunos manuscritos con miniaturas, sería su carácter propagandístico ${ }^{52}$.

Igualmente, Galván, hace referencia a la falta de veracidad en la labor de recopilación de los documentos, citando como ejemplo el libro de los testamentos de la catedral de Oviedo, y muestra su extrañeza, apoyándose en las tesis de Serafín Moralejo ${ }^{53}$, ante el hecho de que un documento de carácter administrativo o instrumental presente tan cuidadas miniaturas. Aquel incide entonces en buscar la relación entre el poder y el arte, imprimiendo a los mismos un carácter político-propagandístico.

Por otro lado, la reunión de los documentos en un mismo volumen facilita la localización y empleo de los diplomas del archivo, evitando el uso continuo y manejo de los originales, permitiendo un mejor funcionamiento de la institución. Esta utilidad queda patente tras el estudio de su organización interna. Algunos manuscritos se presentan redactados a dos columnas, con titulillos en tinta roja, iniciales ornamentadas, índices, «en definitiva, este tipo de libros está pensado para facilitar la búsqueda de cualquier parte de su contenido» ${ }^{54}$. Sáez se refiere a lo que la profesora Mendo Carmona denomina función archivística de los códices diplomáticos ${ }^{55}$.

Los cartularios memoria o los cartularios crónica, aquellos que guardan la historia de las donaciones recibidas que deberán ser preservadas para el futuro; aquellos que conservan la memoria de los donantes, reyes, eclesiásticos, nobles, etc.; y aquellos que preservan la memoria de sus promotores o comitentes, ya sean obispos, abades u otras personas; desearán no

51. F. Galván, La decoración miniada en el libro de las estampas de la catedral de León, León, 1997.

52. Galván, La decoración miniada..., op. cit., 20.

53. M. Díaz, F. Alsina y S. Moralejo, Los Tumbos de Compostela, Madrid, 1985, 45.

54. Sáez, “Origen y función..., op. cit., 18.

55. C. Mendo, "El cartulario como instrumento archivístico", Signo. Revista de historia de la cultura escrita, $15,2005,119-137$. 
solo recordar hechos memorables, sino también «crear una nueva memoria histórica tapando y olvidando aquello que no interesa o que incluso molesta ${ }^{56}$.

Resumiendo, las funciones que el profesor Sáez avanzaba en sus indagaciones, serían aquellas relacionadas con el fin jurídico, la conservación de los originales, la ilegibilidad de los mismos, el deseo de ostentación, la conservación de la memoria y la administración archivística.

La doctora Concepción Mendo Carmona, legataria de los estudios de Emilio y Carlos Sáez, en su artículo El cartulario como instrumento archivístico, amplía, notablemente, la idea de génesis del cartulario ante la necesidad de una herramienta de uso en el archivo: «El cartulario será un nuevo instrumento cuya finalidad es hacer un uso más metódico de los documentos conservados en los archivos para que las instituciones puedan conocer y hacer valer sus derechos de propiedad obtenidos mediante privilegios e inmunidades... ${ }^{57}$.

Analizando la naturaleza jurídico-administrativa del cartulario, ligando la confección del mismo a la conservación de los documentos en tanto que estos representan los bienes y derechos del comitente y relacionando su génesis con periodos de inestabilidad política, reformas culturales, o administrativas, situaciones de crisis, etc., la profesora Mendo desarrolla un completo análisis del cartulario como instrumento archivístico y respuesta a tal pérdida de derechos.

Este contexto de creación habrá de observarse bajo el manto de normativas, reglas y procedimientos de obligado cumplimiento para las instituciones que compelen a ordenar la formación de estos compendios; pautas canónicas reguladoras también de los archivos así como otras dimanadas de los capítulos generales de las principales órdenes monásticas, que habrán de estudiarse en profundidad, y en cada caso, si la pretensión es entender porqué ciertos códices diplomáticos atienden a determinadas características y no a otras..$^{58}$

56. Sáez, “Origen y función..., op. cit., 19.

57. Mendo, "El cartulario..., op. cit., 122.

58. A lo largo de la historia encontramos particulares fueros y constituciones, de carácter civil, eclesiástico, pautas canónicas de órdenes monásticas, etc., que motivan especialmente la producción de códices diplomáticos o que impulsan su evolución. En ellas hallaremos referencias, en ocasiones implícitas, a las funciones que debe desarrollar un archivo en justificación de su existencia así como obligaciones relativas a sus labores con especial indicación a sus instrumentos de descripción. En el mundo secular, a más del Fuero juzgo, se hallarán directrices encaminadas a la buena marcha y organización de los archivo en las Partidas (xIII) o en la Prelación de fuentes de Alcalá (xIV). A principios del s. XVI, una pragmática de los Reyes Católicos ordena a todos los concejos de realengo que trasladen en un libro todos aquellos documentos que afiancen derechos y privilegios. Revela la prof. Sanz Fuentes en su artículo supra cit., Cartularios: historia y falsificación..., 148, que resultado de esta orden podría ser, entre otros muchos, el denominado tumbo de los Reyes Católicos del Archivo Municipal de Écija, en el que se presentan, «junto con el repartimiento del término y el fuero que Alfonso X le otorga, todos los privilegios concedidos por sus sucesores y todos los pleitos de términos mantenidos con los concejos limítrofes, es decir, todos los títulos en los que el concejo astigitano fundaba su territorialidad y su jurisdicción».

Se ordena así y observa, especialmente en las Definiciones de la Congregación de Castilla (Sanz, "Cartularios: historia y falsificación... ”, op. cit., 131 y L. Sagalés, Estructura institucional y legislación sobre archivos 
Por otro lado, Mendo progresará en el concepto de «cartulario» y «códice diplomático» ampliando considerablemente las observaciones de su predecesor. Si bien reconoce que aún queda mucho por estudiar al respecto y que no existen definiciones rigurosas, trata de buscar el origen del término «tumbo» en el griego «túmulo», siguiendo las tesis de autores anteriores por referencia al tamaño de estos libros que se ven obligados a guardar «tumbados» en las librerías. En este sentido Catón, en su reconstrucción del tumbo colorado de Santiago, citando el colofón del mismo: sic inueni in alio loco scripto, quod in beati Iacobi thesauro et in eius tumio permanet ${ }^{59}$, prefiere establecer una relación entre este término y el significado de la palabra «tombo» portuguesa, que a su vez procederá directamente de la latina «tomes», del

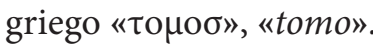

Sobre el término «becerro», Mendo Carmona repasa las concepciones anteriores añadiendo una nota de aviso interesante: «Lo cierto es que el uso de la nomenclatura becerro se extiende a partir de la Baja Edad Media hasta finales del siglo xviII y hace fortuna entre los encargados de archivos y bibliotecas de la Edad Moderna para hacer referencia y denominar como tales tanto a los cartularios, libros de apeos y libros censales, como a los catálogos e inventarios de $\operatorname{archivos»~}{ }^{60}$.

de la Congregación Cisterciense de San Bernardo de Castilla, en Memoria ecclesiae. Órdenes Monásticas y Archivos de la Iglesia (II), 7, 1995, 198), la redacción de un libro llamado «Libro de tumbo»o «Libro maestro», en el que figuren la memoria de la fundación del monasterio, sus privilegios e inmunidades, sus cargas, hacienda, rentas, los bienes y posesiones, jurisdicciones, derechos y todo aquello con la relación de las escrituras que se encuentren en el archivo sobre cada asunto, y en qué lugar se encuentran. Y tan celosos debieron ser los cistercienses en su empeño por atender y custodiar sus archivos que nobleza y realeza confiarán a estos sus asuntos económicos y jurídicos. El caso del monasterio de Poblet es quizá el mas notorio de los estudiados en relación a lo que se pretende ilustrar, pues al margen de ostentar sus miembros cargo de vicarios generales del cister en Aragón y limosneros reales en la corte de Pedro IV, no solo estaban, tanto el abad como los monjes, exentos de juramentos en los pleitos y juicios (siendo considerada su palabra más legítima que un juramento) sino que, ya por privilegio de Pedro II, le fue concedido el título de notario real y escribano público al monje con cargo de archivero de esta institución; datos en conjunto que atestiguan en esta comunidad la valía de su archivo y del archivero para ella, para la orden y para el rey. Véase J. Finestres, Historia de el real monasterio de Poblet, ilustrada con dissertaciones curiosas (...), Cervera, por Joseph Barber, 1753, t. 2, 209, en la que puede leerse: «Estando otra vez en Montblanch el Serenissimo Señor Rey Don Pedro à 14. de Noviembre de el siguiente año 1207. Y cumpliendo assimismo el Abad Don Pedro con la obligacion de ofrecerle su Persona, y Monasterio, le otorgò su Magestad un Privilegio, en que concede la prerogativa de Notario Real, y Escrivano publico à qualquiera Monge, que el Abad destinare para Archivista de el Monasterio; y manda expressamente, que à qualesquiera Escrituras, que el dicho Archivista actuare se les dè la misma fee, que à los Instrumentos actuados por los Notarios, ò Escrivanos publicos de su Reyno, como puede verse en el Apend. Cap. i. n. ii. [sic. En realidad se trata del n. xi. La transcripción del documento latino original puede leerse íntegro en la página $416 \mathrm{del} \mathrm{mismo]».} \mathrm{Otro} \mathrm{caso} \mathrm{no} \mathrm{tan} \mathrm{notorio}$ se localiza en el monasterio de Santes Creus (de la misma orden del Císter) a cuyo archivero concedía el mismo Pedro II, en el año 1210, obligaciones de notario público.

59. Fernández, El llamado Tumbo Colorado..., op. cit., 266.

60. C. Mendo, "Los tumbos medievales desde la perspectiva archivística", en Jornadas científicas: documentación jurídico-administrativa, económico financiera y judicial en el reino castellano-leonés. 
A la luz de lo cual, y siempre que se acerque al estudio de un becerro, se debe preguntar si realmente lo es o si su denominación ha podido ser alterada en el tiempo. En el mismo ensayo supra cit., sobre la reconstrucción del tumbo colorado compostelano, el prof. Catón mostrará claros ejemplos de estas alteraciones.

En cuanto a las atribuciones del cartulario como elemento clave en la administración de los promotores, la preservación de la memoria y la identidad, el fenómeno del «cartulario crónica», la ostentación y la preservación de los originales, vuelven a ser, para Mendo, funciones intrínsecas y principales del mismo.

Hay que destacar una última idea que trasciende sobre las aportaciones de esta autora y es el posicionamiento del cartulario como elemento vital en el archivo: «El cartulario responde a veces a la necesidad de organizar y clasificar los documentos del archivo que en ese momento se encuentra en una situación de desorden generalizado que impide la localización de los títulos cuando se necesitan ${ }^{61}$.

El cotejo de la estructura interna de diversos tumbos y cartularios le lleva a pensar que estos proporcionan una imagen fiel de cómo estaba ordenada la documentación original en el momento de la copia, y que «la organización de los documentos radica en la importancia de los mismos para la hacienda y dotación de la institución ${ }^{62}$. Por lo tanto, no resultaría complicado imaginar la disposición y organización interna de un archivo de un determinado monasterio si se observa la estructura interna de sus cartularios.

Enriquecer el conocimiento relativo a la copia de códices diplomáticos, los procesos y funcionamiento de los escriptorios y de los archivos custodios mediante el estudio de estos y aún más allá, su reconstrucción, es lo que ofrece David Peterson tras sus investigaciones sobre el monasterio de San Millán de la Cogolla, su becerro gótico y su becerro galicano ${ }^{63}$.

Este autor declara al becerro galicano reflejo de la inestable y confusa realidad patrimonial e histórica del monasterio, consecuencia de su condición fronteriza, relacionando la documentación custodiada en el archivo, ambos becerros y la situación del cenobio en el momento de redacción de los códices. Peterson reconstruye el desaparecido becerro gótico a partir del trabajo y referencias previas de un archivero del s. XVIII así como del manuscrito galicano; se acerca a su proceso de confección, a su cartularización, alcanzando conclusiones significativas.

Peterson, consciente de los inconvenientes que conlleva organizar los diplomas insertos en un cartulario cronológicamente para su edición, al romper con ello la estructura interna del mismo, edición en la que además pueden incluirse otros diplomas ausentes en el

(S. X-XIII), Madrid, 2002, 170 .

61. Mendo, "Los tumbos medievales..., op. cit., 186.

62. Mendo, "Los tumbos medievales...", op. cit., 186.

63. D. Peterson, "Reescribiendo el pasado. El Becerro Galicano como reconstrucción de la historia institucional de San Millán de la Cogolla", Hispania. Revista española de historia, 69/233, 2009, 653-682. "El Becerro gótico de San Millán. Reconstrucción de un cartulario perdido", Studia historica. Historia medieval, 29, 2011, 147-173. Toponimia vasca medieval: novedades del Becerro Galicano de San Millán de la Cogolla, en Anuario del Seminario de Filología Vasca Julio de Urquijo: International journal of basque linguistics and philology, 1, 41, 2007, 289-322. 
códice pero referentes al mismo monasterio, creando una colección diplomática «facticia», facilitando el estudio de la institución pero posibilitando en gran medida la perdida de la información que la estructura misma del cartulario aporta; aboga por «considerar los cartularios como un género con sus propias características, cuya estructura es importante para aprehender tanto su contenido como su finalidad. Finalidad que no tiene por qué ser necesaria o exclusivamente la de conservar textos antiguos, sino que refleja las preocupaciones y por tanto diversos aspectos de la realidad del momento de redacción $»^{64}$, incluido el estado del monasterio y el estado de su archivo en el momento de su copia.

Las reconstrucciones o propuestas de reconstrucción de códices diplomáticos perdidos o desconocidos ${ }^{65}$ constituyen ejemplos motivados por el cambio en las metodologías de análisis de las fuentes, así como de la mirada bajo la que se observan los códices diplomáticos en estos últimos decenios y, en dichas reconstrucciones, el estudio de la presencia y organización del archivo originario y del entorno social y político del momento son de consideración obligatoria. Las comparativas y estudios conjuntos entre o de originales, análisis profundos de cartularios y del marco histórico de la institución productora en el momento de su copia, ofrecen resultados no considerados hasta ahora, «las posibilidades de conocer la organización de los archivos medievales y el propio contenido de algunos de ellos se han visto ampliadas en los últimos años por el estudio, entre otras fuentes, de sus antiguos instrumentos de descripción ${ }^{66}$.

En este sentido, la doctora Elena Rodríguez Díaz, estudia y compara cuatro códices diplomáticos de la sede episcopal de Oviedo, a saber, el libro de la regla colorada, el libro de los privilegios, el libro de las constituciones y el libro becerro. Tras una profunda descripción y examen de los mismos, las conclusiones que obtiene son no menos que sorprendentes: aunque los cuatro códices presentan un contenido textual muy similar, «cada libro tenía una preparación material diferente, porque cada códice tenía una función distinta» ${ }^{67}$.

Rodríguez Díaz, doctora de la Universidad de Huelva, destaca en su labor por introducir en sus estudios, sobre códices y manuscritos, una metodología poco frecuente hasta el momento. En uno de sus últimos artículos ${ }^{68}$ proyecta el análisis de 191 códices, buscando nexos entre ellos, con el objetivo de organizar sus dataciones. Igualmente, presenta, junto a

64. Peterson, "Reescribiendo el pasado..., op. cit., 659.

65. E. Ramírez, "Propuesta de un 'Cartulario 0’ de los Reyes de Navarra”, en Les cartulaires médiévaux. Écrire et conserver la mémoire du pouvoir, le pouvoir de la mémoire. Los cartularios medievales. Escribir y conservar la memoria del poder, el poder de la memoria, sous la direction de V. Lamazou-Duplan et E. Ramírez Vaquero, Pau, 2013, 95-114; Fernández, El llamado Tumbo Colorado..., op. cit.; E. Ruiz, "En torno al inventario archivístico de San Salvador de Oña (s. xv)", en Homenaje a M. ${ }^{a}$ Angustias Moreno Olmedo, Granada, 2006, 513-523.

66. M. Calleja, "Noticias documentales del archivo capitular de la Catedral de Oviedo (ss. IX-XII)", Acta historica et archaeologica mediaevalia, 25, 2003-2004, 542.

67. E. E. Rodríguez, "Elaboración, uso y función de los códices de scriptorium episcopal ovetense a fines del siglo xiv", Historia. Instituciones. Documentos, 19, 1992, 411.

68. E. E. Rodríguez, "Indicios codicológicos para la datación de los manuscritos góticos castellanos", Historia. Instituciones. Documentos, 31, 2004, 543-588. 
la doctora María Luisa Pardo, una comparativa de 35 códices sevillanos que abre la puerta al estudio de la producción libraria en Sevilla durante el s. $\mathrm{Xv}^{69}$.

Una metodología basada en el análisis comparativo de muestras elevadas de códices y no los estudios unitarios que vienen realizándose hasta el momento capacitan a la autora para establecer diferencias y similitudes entre los mismos a mayor escala. Introduciendo, además, variables como el entorno social, económico y cultural de la época, logra profundizar aún más en las conclusiones relativas al origen, procesos de elaboración y funciones, obtenidas hasta el momento.

Hoy día se continúan realizando investigaciones profundas relativas a las particularidades de los cartularios como objetos de estudio o a la problemática que suscitan ciertos aspectos, como los citados en párrafos anteriores. Además, salen a la luz nuevas ediciones, más completas y rigurosas, de códices que han permanecido hasta el momento huérfanos de imprenta y también de aquellos ya bien conocidos por los historiadores.

\section{Conclusiones}

Sintetizando brevemente lo expuesto a lo largo de este artículo, podría concluir de la siguiente manera:

Queda manifiesto que abundan los estudios sobre códices diplomáticos concretos, no así, los estudios generalistas. La conceptualización de los códices diplomáticos, ya nos refiramos a cartularios, becerros, tumbos, etc., no está definida aun, ni lo ha sido a lo largo de los últimos siglos; cuestión demandada en los foros y círculos de discusión actuales.

Sí encontramos superada la manera de entender el concepto de «cartulario» como conjunto de fuentes de una institución o colección diplomática y no como objeto de estudio con materialidad propia. No así la conceptualización individualizada de cada uno de los códices diplomáticos independientemente de su denominación generalista, particularidad peninsular esta que no favorece la resolución del conflicto resultante de contar con términos que vienen siendo utilizados como sinónimos, como son «cartulario», «becerro», «tumbo», etc. En este caso, por tanto, no se consigue establecer una sistemática consensuada entre los investigadores que han dedicado y dedican su esfuerzo a los códices diplomáticos.

Además, resulta beneficioso establecer una clasificación completa de estos códices. Los estudios sobre su contenido u organización interna ofrecen la posibilidad de establecer diversas tipologías. Así, la estructura textual del documento puede distribuirse de manera cronológica, geográfica o temática. Los estudios de las instituciones productoras de los manuscritos también reportan una segunda tipología: eclesiásticos, monásticos, de órdenes militares, nobiliarios, municipales, etc. Una tercera y última será aquella que distinga entre cartularios conformados con los documentos originales, aquellos que contienen tan solo re-

69. E. E. Rodríguez y M. L. Pardo, "La producción libraria en Sevilla durante el siglo xv: artesanos y manuscritos", en Scribi e colofoni. Le sottoscrizioni di copisti dalle origini all'avvento della stampa. Atti del seminario di Erice, $x$ colloquio del Comité International de Paléographie latine (23-28 ottobre 1993), a cura di E. Condello e G. de Gregorio, Spoleto, 1995, 187-221. 
gestos o copias parciales o, por último, los que contienen copias íntegras de los documentos conservados en el archivo de la institución.

La razón por la cual el códice diplomático es producido y la función que va a desempeñar en la institución serán la causa y motivo de la elección de una u otra estructura interna del mismo, de la preferencia por un tipo u otro de «cartularización» y de la materialidad del mismo. A las funciones estudiadas por los especialistas del s. XIX, como la conservación y la función jurídico-administrativa, se han de sumar la ostentación, la función memoria o crónica y la finalidad archivística, deducidas estas de las exploraciones y los estudios descriptivos más modernos, así como de la superposición de estos estudios a los acontecimientos históricos del momento en el que el códice diplomático se produce (práctica observada solo en el último siglo); metodologías estas favorecidas por el uso de nuevas tecnologías no aplicadas hasta el momento.

Recientes revisiones sobre los conceptos de falsedad, autenticidad, veracidad, falsos diplomáticos, copias alteradas, etc., demandan un nuevo diagnóstico para los documentos y códices diplomáticos tildados en siglos anteriores de poco convenientes para las investigaciones, obligando al historiador o filólogo actual a observar desde una óptica crítica y reflexiva los resultados de tales afirmaciones.

Por último, la edición crítica de estos manuscritos se despliega en auge hoy día, arropada por los avances que las áreas de la Paleografía, la Diplomática, la Archivística, la Cultura Escrita y la Documentación, siguen alimentado al conocimiento de esta materia. Las jornadas, coloquios y congresos, valiosos indicadores de la actividad científica actual en el tema que nos ocupa, difieren demasiados interrogantes por resolver, pero también abren cuantiosas puertas por donde continuar nuestro camino. La evolución, en los últimos años, en las maneras de afrontar estas fuentes, los avances en las metodologías y sistemas de investigación y pensamiento son notorios y fructíferos. 